\title{
Enquadramentos midiáticos e sua influência sobre a consolidação de direitos de crianças e adolescentes
}

\author{
\begin{tabular}{c}
\hline \hline Danilo Rothberg \\
Departamento de Ciências Humanas \\
Faculdade de Arquitetura, Artes e Comunicação \\
Universidade Estadual Paulista \\
\hline \hline
\end{tabular}
}

Resumo: Este artigo traz uma contribuição à compreensão do percurso de reconhecimento dos direitos de crianças e adolescentes no Brasil, no qual têm sido observadas representações simbólicas que, com frequência, são criadas, modificadas ou popularizadas pelas diversas mídias. Foram pesquisados com análise de enquadramento os jornais impressos de maior circulação no estado de São Paulo em um período após quase 20 anos de vigência do Estatuto da Criança e do Adolescente (ECA). Os resultados sugerem que o ECA enfrenta obstáculos à sua consolidação, na forma de coberturas jornalísticas superficiais e fragmentadas de acontecimentos que deveriam ser contextualizados em relação às políticas públicas da área e seu específico entendimento de causas possíveis e soluções cabíveis.

Palavras-chave: mídia; enquadramento; direitos sociais; crianças; adolescentes

\begin{abstract}
This article brings a contribution to the comprehension of the path of recognizing the rights of children and adolescents in Brazil, in which there have been seen symbolic representations that often are created, modified or popularized by the media. Newspapers with the largest circulation in the state of São Paulo in a period after almost 20 year of the Statute of the Child and Adolescent (ECA) coming into force were investigated with framing analysis. Results suggest that the ECA faces obstacles to its consolidation, in the form of superficial and fragmented media coverage of events that should be contextualized in relation to public policies and their specific understanding of causes and possible solutions applicable.
\end{abstract}

Keywords: media; framing; social rights; children; adolescents 


\section{Introdução}

Em 13 de julho de 1990, foi promulgada a Lei Federal 8.069, conhecida como Estatuto da Criança e do Adolescente (ECA). Quando, em 2008, foram celebrados seus 18 anos, notava-se eventualmente no cenário midiático brasileiro um quadro de insuficiência de informações capaz de reforçar argumentos em defesa da redução da maioridade penal (fixada pela Lei 8.069 em 18 anos de idade), que, nos anos posteriores, não foram necessariamente esvaziados, embora ainda sejam esperados estudos empíricos para lançar mais luz sobre tal processo de formação de opinião pública.

Este artigo traz uma contribuição à compreensão do percurso de reconhecimento dos direitos de crianças e adolescentes no Brasil, que se efetiva, concretamente, através da criação e manutenção de instituições especializadas que têm, no ECA, sua origem e sua definição de atribuições legais. Mas também perpassa o nível das representações simbólicas que assinalam ou ignoram direitos, em construções que são, com frequência, criadas, modificadas, repercutidas ou simplesmente repetidas e popularizadas pelos meios de comunicação.

O estatuto instalou um diferente entendimento das medidas de proteção necessárias àquele público, sujeito de novos direitos e deveres em um contexto de alerta às iniquidades legadas historicamente. A transformação visada pela lei envolve mudanças culturais, que podem, por sua vez, ser incentivadas ou desestimuladas pelos meios de comunicação enquanto veículos de representações e enquadramentos simbólicos.

Caracterizam-se, assim, questões de pesquisa pertinentes: quais são as características da cobertura praticada pelos jornais impressos de expressiva circulação no país quando as estruturas criadas pelo ECA ou seus efeitos práticos estão em pauta? As matérias são abrangentes e apuram os aspectos das políticas públicas relacionadas, incluindo o exame de causas, consequências e responsabilidades envolvidas nos problemas enfocados? Ou meramente se esgotam no registro superficial de infrações cometidas por crianças e adolescentes, sem consideração aos aspectos legais colocados pelo ECA e às circunstâncias sociais relevantes? Ou, ainda, investem na exploração sensacionalista e fragmentada dos fatos?

Essas questões de pesquisa podem ser relacionadas às seguintes hipóteses:

a) Mesmo após o Estatuto da Criança e do Adolescente ter atingido a sua maioridade, 18 anos após sua promulgação, ainda não se efetivaram por completo as mudanças de cultura política que seriam relevantes para a ampla consolidação das políticas públicas originadas na legislação.

b) A resistência às mudanças culturais em questão pode ser em parte estimulada pelas mídias jornalísticas comerciais, as quais ainda adotam conceitos de notícia associados a coberturas superficiais e fragmentadas de fatos e acontecimentos que, à luz do ECA, deveriam ser contextualizados em relação às políticas públicas da área e seu específico entendimento de causas possíveis e soluções cabíveis.

Nesse sentido, foram formulados os propósitos e os métodos da pesquisa que têm seus resultados descritos neste artigo. A investigação aplicou a metodologia de análise de enquadramento sobre os jornais Folha de S. Paulo e O Estado de S. Paulo no período de julho de 2008 a dezembro de 2009, com foco em matérias sobre fatos e acontecimentos que envolveram a violação dos direitos de crianças e adolescentes ou abrangeram questões relacionadas às normas e à atuação das estruturas criadas pelo Estatuto da Criança e do Adolescente. Esses jornais detinham no período a liderança de circulação no estado de São Paulo. A Folha também estava na liderança do ranking brasileiro de 
ROTHBERG, D. Enquadramentos midiáticos e sua influência sobre a consolidação de...

tiragens, com 311 mil exemplares diários, e o Estadão ocupava o quinto lugar no país, com 245 mil exemplares diários, segundo dados da ANJ (Associação Nacional de Jornais) referentes ao ano de 2008 e divulgados pelo Portal Imprensa (NECO, 2009).

Os objetivos foram: a) verificar a qualidade da contextualização composta pelas matérias em relação às causas e soluções apuradas pelos jornalistas no contexto do sistema nacional de preservação dos direitos de crianças e adolescentes, às políticas públicas da área, aos atores sociais envolvidos e a dados e discussões específicas relacionadas, como estatísticas, citações à legislação pertinente e referências a temas atuais como a redução da maioridade penal e a gestão das instituições de privação de liberdade; b) caracterizar e avaliar a potencial contribuição dada pelos meios de comunicação estudados na forma de representações e enquadramentos simbólicos que podem incentivar o aprofundamento de uma cultura política de reconhecimento de direitos de crianças e adolescentes no Brasil ou, ao contrário, desestimulá-lo.

Os resultados sugerem que o ECA enfrenta obstáculos à sua consolidação, na forma de coberturas jornalísticas superficiais e fragmentadas de acontecimentos que deveriam ser contextualizados em relação às políticas públicas da área e seu específico entendimento de causas possíveis e soluções cabíveis.

O percurso do artigo se divide em três etapas. Em primeiro lugar, são retomados três aspectos teóricos relevantes da pesquisa de enquadramentos midiáticos na atualidade, a saber: representações simbólicas, narrativas mitológicas e efeitos de mídia. Em segundo lugar, a metodologia é delineada e os resultados empíricos são apresentados e discutidos. Por último, considerações finais sintetizam as contribuições do artigo.

\section{Representação, mito e efeitos de mídia}

Os enquadramentos podem ser caracterizados como "marcos interpretativos mais gerais construídos socialmente que permitem às pessoas fazer sentido dos eventos e das situações sociais" (PORTO, 2004, p. 78). Um enquadramento (framing) é como um pacote interpretativo, uma ideia central que organiza a realidade dentro de determinados eixos de apreciação e entendimento, e é construído através de procedimentos como seleção, exclusão e ênfase de determinados aspectos e informações, de forma a compor perspectivas gerais através das quais fatos e circunstâncias são dados a conhecer (Gamson; Modigliani, 1989; Azevedo, 2004).

Os enquadramentos podem ser categorizados, através de verificação empírica, em formatos específicos, como: quadros de conflito (quando retratam os políticos como eternos personagens em disputa, sem mais considerações às políticas públicas envolvidas em determinado arranjo de forças); jogo (os personagens são retratados como agentes movidos unicamente por estratégias competitivas em busca de vantagens particulares); e episódicos (quando fatos e conjunturas de grandes repercussões recebem tratamento superficial e são enfocados somente a partir de seus traços extravagantes, pitorescos ou sensacionalistas).

Em oposição aos quadros de conflito, jogo e episódicos, situam-se os enquadramentos temáticos, na forma de abordagens contextualizadas, plurais e abrangentes, que relacionam antecedentes e pressupostos de políticas públicas, avaliam implicações e consequências, examinam alternativas e critérios de comparação etc. (IYENGAR, 1990; 1991). 
Três aspectos do conceito de enquadramento são relevantes para fundamentar a compreensão sobre como o jornalismo age na atualidade com a construção de frames capazes de influenciar a maneira pela qual os leitores de notícias percebem os acontecimentos. Em primeiro lugar, está a vinculação dos estudos de frames às teorias da representação, segundo as quais o conceito de enquadramento é tributário de uma extensa trajetória de teorização sobre as formas de exercício de poder na sociedade contemporânea. Em segundo lugar, está a associação entre enquadramento e narrativa, segundo a qual os frames são um artifício necessário tanto ao jornalista quanto ao consumidor de notícias, porque o primeiro precisa de uma estrutura acessível em torno da qual dispor as informações, e o segundo depende de uma concatenação aparentemente lógica das informações para atribuir sentido à sua experiência. Em terceiro lugar, deve ser posta uma relevante separação teórica entre frames e seus efeitos, sem a qual se corre o risco de aceitar acriticamente a ascendência do jornalismo como fonte central de elementos para a organização da experiência do cotidiano.

Esses três aspectos serão brevemente retomados, a fim de situar entre eles a relevância das pesquisas de enquadramentos da cobertura jornalística de fatos e acontecimentos relacionados à preservação de direitos de crianças e adolescentes.

\section{Teorias da representação}

As percepções da realidade sensível, embora aparentemente circunscritas ao indivíduo que as detém, podem ser compartilhadas coletivamente e assim assumem o caráter de vetor de socialização, ao integrar diferentes visões de mundo em uma mesma perspectiva. Tais percepções carregam significados e imagens relativamente estáveis e têm o potencial de se impor com maior ou menor resistência ao indivíduo, que, com frequência, depende de assimilá-las adequadamente para interagir de forma bem. sucedida com a sociedade (FRANÇA, 2004).

Relações e status sociais possuem significado graças à permanência das representações simbólicas, que são alimentadas por esferas superestruturais como escola, família, religião e mídia. A educação, em especial, adquiriu a função de zelar pela reprodução de crenças e valores fortemente atados a representações de classe social (BOURDIEU; PASSERON, 1982), que relacionam causas e consequências em trajetórias escolares e profissionais a posições herdadas socialmente, às quais os indivíduos deveriam se resignar, uma vez que teriam sido programadas para eles.

Mas a tese da centralidade dos meios de comunicação na sociedade como fonte de conhecimento reivindica para a mídia o poder de influenciar as representações simbólicas de maneira mais intensa do que a educação seria capaz, de forma que, embora as perspectivas perpetuadas no âmbito escolar ainda sejam, obviamente, objeto de muitos estudos, os pesquisadores da comunicação tendem a considerar que a mídia adquire proeminência como fonte de representações (LIMA, 2001).

A mídia comparece na abordagem construtivista das teorias da representação, no contexto da revisão de Hall (2002), para quem as abordagens reflexiva e intencional, apesar de seus méritos, devem ser preteridas em favor do construtivismo. No âmbito da abordagem reflexiva, o sentido existe de forma intrínseca aos objetos, e as representações apenas espelham o conteúdo da realidade. Essa ótica, embora ultrapassada, ainda é útil para lembrar que pode existir alguma correspondência objetiva entre representado e representação, apesar de superficial, fugaz e, frequentemente, errática. Para a abordagem intencional, um emissor tem o poder de determinar o significado de sua expressão, ao impor 


\section{ROTHBERG, D. Enquadramentos midiáticos e sua influência sobre a consolidação de...}

certas distinções de sentido. Essa visão, embora seja útil para lembrar a relativa capacidade de um emissor orientar a recepção de sua mensagem, não se sustenta diante do fato de que a compreensão final é influenciada por diversos fatores, que vão desde as perspectivas concorrentes em disputa no meio de transmissão ou interatividade até os filtros advindos conscientemente ou não do sujeito da recepção, passando pela possibilidade de ruídos e interferências em todo o processo, intencionais ou acidentais.

Somente a abordagem construtivista faz ver que

são os atores sociais que usam os sistemas conceituais de sua cultura e os sistemas de representação, como o linguístico e outros, para construir sentido e fazer do mundo algo pleno de significado (HALL, 2002, p. 25).

Se o significado é, afinal, construído socialmente através da interação entre os indivíduos e entre estes, as instituições e os agentes sociais, as mídias assumem papel central na construção e reprodução de representações - embora seja igualmente relevante nesse contexto teórico a ressalva de que o cenário criado pela mídia, sozinho, tende a não ser capaz de determinar por completo as representações que os indivíduos vão nutrir para si próprios no final do processo, dado o caráter complexo e dinâmico da produção simbólica na sociedade.

As representações têm sido entendidas como simulacros, porque simulam a existência de uma dada realidade de forma tão eficaz que tendem a se confundir com os próprios objetos representados:

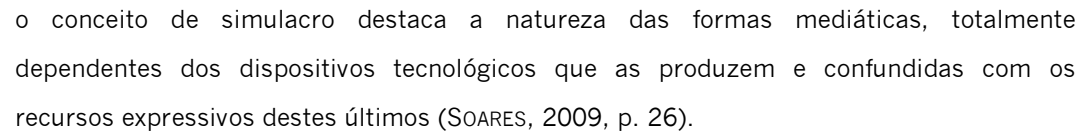

As representações se tornam essenciais ao funcionamento da sociedade na "produção social das ideias, por meio de elaborações discursivas, que sancionam percepções sobre coisas, pessoas, ideias, estados e processos" (SOARES, 2009, p. 15). Uma vez propagadas, as representações estariam livres do dever de serem permanentemente referenciadas à realidade da qual tomam o lugar. Bastaria, ao organizador do discurso, reunir os elementos usualmente associados a determinada perspectiva para trazer à tona todo um conjunto preexistente de visões, crenças e valores, que assim adquirem um sentido operacional para colaborar na construção e na expressão de entendimentos particulares sobre novos acontecimentos.

O automatismo da reprodução de representações assinala a existência de um estoque razoavelmente constante de perspectivas a serem acessadas, sempre quando for necessário enquadrar a novidade nos limites de um contexto previamente composto. Mas nem por isso se pode dizer que tal repositório seja completamente constante no espaço e no tempo. Com frequência, as representações têm base territorial, sendo a nação, muitas vezes, seu domínio principal, de maneira que as culturas nacionais se revelam como fundamento absoluto de simulacros (ainda que as diferenças regionais também sejam de enorme importância). E as representações podem ser transformadas ao longo do tempo, já que novos acontecimentos podem trazer perspectivas radicalmente distintas de consideração de relações e papéis sociais, causas e consequências de fenômenos econômicos e políticos etc.; e novos atores sociais podem ver seu poder de influência crescer sobre as interpretações que passarão, de forma muito dinâmica, a ser mais correntes em dado contexto. 
Justamente no embate entre setores sociais que utilizam suas próprias representações da realidade como dispositivos para a transformação da realidade, a mídia se torna instrumento de exercício de poder simbólico (BOURDIEU, 1998). Os agentes sociais lutam para fazer valer sua imagem de mundo e, dessa forma, buscam impor representações que orientem políticas de governo dirigidas a mudar o curso da vida social, econômica e política no sentido que esperam. Mudar categorias de percepção da realidade é um passo importante para efetivamente transformar a realidade. No cenário construído pelas mídias, a luta pelo poder simbólico equivale à luta pelo poder de transformação de políticas concretas.

Hall (2002) acentua a relevância de atentar para as relações entre os aspectos que compõem as representações. Uma perspectiva específica surge exatamente em torno das conexões entre determinados elementos de um único objeto. Para Hall (2002), a representação é relacional, o que lembra Bourdieu (1998), para quem o próprio real é relacional. As propriedades intrínsecas de um objeto não podem ser identificadas senão através do exame das relações entre as partes que o formam. Disso vem a definição de que representações são mapas conceituais, artifícios dotados de noções que se relacionam umas com as outras e nos orientam a agir e a raciocinar. Os mapas são, em princípio, individuais: cada um constrói e zela pela organização de seu próprio. Mas os indivíduos não extraem do vazio os elementos que farão parte de seus mapas conceituais. A cultura é o substrato coletivo que fornece significados compartilhados, de modo que a representação é sempre cultural.

Cultura política, especificidade que importa aqui, pode ser entendida como estoque de representações que envolvem nexos embebidos na vida social de uma nação, capazes de conferir sentido às práticas de atores sociais, políticos e econômicos, passando pela afirmação de determinadas perspectivas de compreensão de papéis e relações sociais. Se, na acepção singular de Bobbio, Matteuci e Pasquino (1997, p. 306), cultura política é o "conjunto de atitudes, normas, crenças, mais ou menos largamente partilhadas pelos membros de uma determinada unidade social e tendo como objeto fenômenos políticos", os conhecimentos e as tendências psicológicas que a compõem podem ser apreciados na forma de representações simbólicas, com valores atados.

As tendências podem ser cognitivas, envolvendo crenças que predispõem à assimilação de conhecimento sobre os papéis assumidos no campo político; afetivas, referentes aos sentimentos atribuídos aos nexos entre relações sociais em dado sistema político; e valorativas, relativas aos juízos e opiniões que acompanham inevitavelmente a inserção política do sujeito, embora não necessariamente assumidos como tal (BoBBIO; MATTEUCl; PASQUINO, 1997).

Tal caracterização não deve conduzir à ideia de que a cultura política de um país possa ser homogênea. Em geral, pode ser verificada a existência de muitas subculturas, delineadas por correntes diferenciadas de pensamento, de maneira que novamente a luta pelo poder simbólico deve ser vista como central aqui: o embate entre subculturas revela que forças políticas lutam por impor às demais sua própria representação, alçando-a à condição de perspectiva mais justa, exata, fiel ou simplesmente a única correta.

Aqui, o conceito de representação encontra o conceito de enquadramento. Representar não é apenas expressar, mas também deixar de expressar; é reter, cortar, selecionar e encaixar a partir do que não foi eliminado. E o que foi cortado pode ser mais importante na composição do significado contido 
ROTHBERG, D. Enquadramentos midiáticos e sua influência sobre a consolidação de... em uma representação - que diz mais, justamente, não pelo que revela, mas pelo que omite. "Representações não são informações pontuais, tão somente", indica Soares:

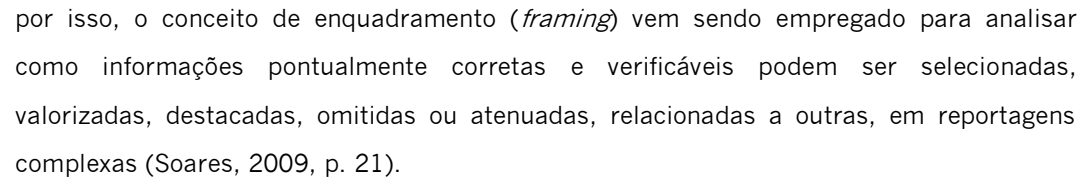

Uma representação é, assim como um enquadramento, uma apropriação particular de sentido que opera vínculos e limpa o terreno simbólico para proporcionar a proeminência de dada perspectiva.

Um acontecimento depende, para ganhar existência na forma de notícia, da disponibilidade de um frame apropriado no repertório do jornalista. Segundo Motta, "Esse caráter reflexivo do enquadramento faz com que a descrição de um evento social seja parte essencial do reconhecimento desse acontecimento enquanto unidade social descritível" (MOTTA, 2010, p. 140).

A seleção de informações operada em uma matéria jornalística veicula uma representação, que nas pesquisas de comunicação e jornalismo passa a ser estudada nos termos de enquadramento. Frames são recortes, aos quais subjazem definições de cenário, juízos de valor, avaliações morais e interpretações valorativas, organizados por uma perspectiva central nem sempre reconhecível imediatamente. Daí a necessidade de que os estudos de enquadramento apliquem metodologias adequadas para identificá-los, considerando que seus componentes se organizam de forma a compor narrativas mitológicas.

\section{Enquadramento e narrativa}

Avaliações e juízos implícitos aos enquadramentos também estão presentes naquilo que Barthes (1993) denominou de mitos, ou concepções gerais baseadas em encadeamentos de causa e efeito, motivações e hipóteses que subjazem a qualquer apreciação de um acontecimento. Em um dos casos analisados por Barthes (1993) e retomado por Hall (2002), a capa de uma revista com um homem negro em farda militar que fita seriamente a bandeira francesa suscita referências a um amplo conjunto de perspectivas, então tidas como elementos de um mito específico, segundo o qual a manutenção do imperialismo francês no continente africano seria uma fonte importante de problemas para a França.

A cena artificial da capa deve ser lida no contexto do mito, trazendo à tona uma diversidade de juízos de valor sobre determinados aspectos da trajetória do país em sua política colonialista. Nesse sentido, o mito é um conjunto de significados socialmente compartilhados que serão, com grande probabilidade, postos em circulação quando um novo dado se relaciona ao preexistente.

Os elementos de um mito devem se vincular uns aos outros de maneira razoavelmente harmônica, para que a explicação por ele proporcionada seja acessível sempre que necessário. No exemplo posto, os benefícios iniciais do colonialismo diante de seu esgotamento histórico precisam estar ligados ao contexto do colapso das potências europeias com a Segunda Guerra Mundial, de maneira que a perspectiva do mito como um todo seja articulada como uma narrativa, ou seja, como uma série de acontecimentos encadeados que favorecem a compreensão do contexto relacionado.

Para a sociologia do jornalismo, a fórmula narrativa arquitetada por uma reportagem é tida como um enquadramento. Ambos são resultados de escolhas estratégicas de construção e expressão de 
sentido, revelando-se como princípios de organização que carregam "definições da realidade social", segundo Tuchman (1999, p. 259). Nesse sentido, o uso do termo narrativa na sociologia do jornalismo para qualificar uma reportagem se diferencia das vertentes exploradas no âmbito da literatura, da semiótica e da crítica do jornalismo como veículo ideológico (SODRÉ, 2009).

Em seu ofício cotidiano, os jornalistas buscam fórmulas narrativas para enquadrar fatos em especial, pinçados da torrente de acontecimentos diários que thes pareceria sem significado aparente caso não fosse possível empregar um frame em particular.

De fato, é muito provável que alguns acontecimentos nunca consigam "ser notícia" porque o catálogo de antigos frames de "estórias" não inclui um frame particular que se thes possa aplicar (TUCHMAN, 1999, p. 261).

Reportagens tidas como narrativas mitológicas, que são, afinal, enquadramentos, evidenciam sua característica de construção cultural, salientam Bird e Dardenne (1999, p. 264). Daí a importância de a pesquisa em jornalismo focar não necessariamente as informações específicas sobre fatos que, no final das contas, se repetem ao longo do tempo, mas sim o arcabouço simbólico mais geral em que os pormenores são arranjados. Bird e Dardenne (1999) sustentam que, obviamente, os dados isolados possuem significado a ser analisado. No entanto, os quadros gerais e mais ou menos constantes de percepção dos fatos são mais elucidativos a respeito do conteúdo do aprendizado proporcionado pela informação jornalística: "poder-se-ia argumentar que a totalidade das notícias como sistema simbólico duradouro 'ensina' os públicos mais do qualquer das suas partes componentes” (BIRD; DARDENNE, 1999, p. 265).

Sustentar que uma matéria jornalística é uma narrativa mitológica e, como tal, carrega consigo enquadramentos particulares que encerram perspectivas bastante específicas de compreensão dos fatos não implica desqualificar a notícia a ponto de considerá-la ficcional. Ao contrário: o uso da narrativa é uma forma de buscar objetividade (TUCHMAN, 1999). O mito se caracteriza por implicar determinadas respostas a questões universais que permeiam o cotidiano. É inevitável que concepções mais gerais sobre a vida em sociedade, inscritas nas narrativas mitológicas contemporâneas, estejam presentes em uma matéria jornalística. Os mitos funcionam como estoque de significados úteis para embalar determinada informação em um frame de compreensão do acontecimento enfocado.

Os critérios de noticiabilidade, ou valor-notícia, contêm inclusive julgamentos sobre a possibilidade de um novo acontecimento ser enquadrado por um mito a que se possa facilmente recorrer. Há aqui um critério de eficiência, necessário à economia de recursos nas redações: o mito provê a rápida codificação do dado bruto em símbolos de fácil reconhecimento pelo público em geral, recorrendo a elementos comuns aos dramas coletivos cotidianos. Segundo Motta, "Os jornalistas utilizam frames narrativos porque, por um lado, eles facilitam sua tarefa de enquadrar a complexidade do mundo" (MOTTA, 2010, p. 137).

Por outro, conscientemente ou inconscientemente, os jornalistas sabem que esses frames dramáticos são rapidamente compreendidos pelos receptores que os utilizam frequentemente no mundo da vida (MOTTA, 2010, p. 137). 
ROTHBERG, D. Enquadramentos midiáticos e sua influência sobre a consolidação de...

No contexto, acredita-se que, na outra ponta do processo, o público estará mais disposto a escolher para leitura, no curto tempo do qual supostamente dispõe, a notícia que mais facilmente estiver embebida em uma narrativa mitológica acessível e atraente.

A narrativa mitológico-jornalística ainda possui lugares previstos para determinados agentes sociais (BIRD; DARDENNE, 1999). Trabalhadores, grevistas, crianças e adolescentes, empresários, indígenas, políticos desse ou daquele partido, ex-mandatários, ministros e uma vasta gama de personagens tendem a assumir posições reservadas a eles, já dadas antes mesmo de o jornalista iniciar a apuração do acontecimento no qual estão envolvidos. As relações entre esses agentes possuem, igualmente, uma demarcação conhecida de antemão. Novamente, cabe salientar que as posições não são estáticas e podem se transformar ao longo do tempo em função das próprias dinâmicas sociais. Mas projetam-se espacial e temporalmente com relativa estabilidade para pavimentar a eficiência do trabalho nas redações.

O emprego de narrativas que simplificam e padronizam, despindo fatos complexos de seus nexos originais a fim de embalá-los para consumo, corresponde a exigências de produção industrial de notícia e assim tem sido estudado em seus efeitos para a vivência democrática.

\section{Enquadramentos e seus efeitos}

A literatura científica de comunicação e política relacionada ao conceito de enquadramento reconhece plenamente que a presença de determinados enquadramentos midiáticos não é suficiente para influenciar de maneira definitiva a percepção que o público vai ter do fato ou acontecimento representado, dada a complexidade da dinâmica da recepção. Tal reconhecimento pode consistir em simples ressalvas teóricas de que certos resultados de pesquisas de enquadramento apenas sugerem a possibilidade de o público pensar de uma forma coadunável com os frames detectados, em meio a outras formas possíveis a serem verificadas empiricamente. Mas o reconhecimento também vem de estudos atentos à recepção ou que, dispondo de dados sobre as perspectivas sustentadas por vastas camadas sociais, procuram ligar os pontos da emissão e da recepção e assim obter uma compreensão mais acurada do processo de persuasão desencadeado por um enquadramento (ALDÉ, 2001; PORTO; 2007a; 2007b).

O processo é conhecido em particular nos termos das mediações, então estudadas como campo em que vivências, ambientes e competências cognitivas influenciam a assimilação de representações:

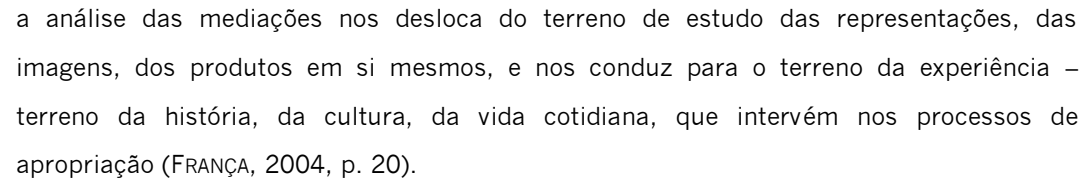

Nessa abordagem, indica França (2004), não cabe analisar somente as representações em si mesmas, mas principalmente as maneiras pelas quais os indivíduos lidam com elas, com o emprego de metodologias qualitativas, como entrevistas e grupos focais.

Os estudos de lyengar (1990; 1991) foram pioneiros ao traçar relações entre enquadramentos e determinadas percepções construídas pelo público a eles exposto, de forma a contribuir para a 


\section{OPINIÃO PÚBLICA, Campinas, vol. 20, no 3, dezembro, 2014, p. 407-424}

elaboração, ainda em progresso, de uma teoria do enquadramento como teoria sobre os efeitos da mídia (SCHEUfELE, 1999). Segundo lyengar (1991), indivíduos expostos a enquadramentos episódicos de reportagens televisuais, centrados em aspectos pontuais dos problemas, marcados pela ênfase dramática nas consequências particulares sofridas por alguns cidadãos e desprovidos de contextualização adequada, mostraram-se menos propensos a atribuir a responsabilidade por determinados problemas sociais aos mandatários por eles responsáveis.

Ou seja, a superficialidade e a falta de contexto dos enquadramentos episódicos tornavam mais difícil, ao telespectador, perceber os contornos das políticas implementadas e identificar seus agentes e as circunstâncias nas quais foram formuladas e executadas.

Ao desencorajar os telespectadores a atribuir responsabilidade por questões nacionais aos atores políticos, a televisão diminui o controle do público sobre seus representantes eleitos e as políticas que adotam (IYENGAR, 1991, p. 3).

Os enquadramentos temáticos tendiam a gerar o efeito contrário: ao proporcionar um tratamento mais abrangente dos problemas sociais, desnudando nexos entre causas e consequências e provendo contexto com mais profundidade, as abordagens temáticas estavam associadas com mais frequência a percepções mais acuradas sobre as responsabilidades na escolha e na condução de políticas públicas.

A dificuldade de visualizar os responsáveis foi logo associada ao fenômeno da apatia e do cinismo diante da política. Para o público em geral, se não era possível identificar responsabilidades, a saída seria ocupar-se com a vida cotidiana e deixar a política a cargo dos políticos (muito embora, com um ceticismo constantemente alimentado pelo noticiário, muitos acreditavam que nem os políticos seriam capazes de assumir ou compreender suas próprias atribuições).

A teoria da espiral do cinismo, como Cappella e Jamieson (1997) a popularizaram, avança na proposição de bases empíricas advindas da psicologia cognitiva para o enquadramento como teoria dos efeitos de mídia. Para Cappella e Jamieson, "o conhecimento sobre política é organizado como conexões entre conceitos ou construtos na memória [...] que se diferenciam no quão facilmente podem ser acessados" (CAPPELLA; JAMIESON, 1997, p. 59). As conexões são atadas a aspectos emocionais pessoais e dependem de ativação adequada para operar reflexões e juízos sobre a política em um dado momento e em uma dada sociedade.

Os enquadramentos, ao selecionarem certos aspectos dos acontecimentos e não outros, ativam algumas conexões e mantêm outras inativas, estimulando alguns raciocínios e mantendo outros pensamentos fora do espectro de avaliações possíveis de um acontecimento. Ao longo do tempo, a exposição repetida a certos enquadramentos tende a consolidar a aparente pertinência de algumas conexões, de maneira que o acesso a elas tende a ser mais fácil, desencorajando juízos alternativos. 0 cinismo viria como forma de organizar uma percepção abstrata do mundo político, na qual responsabilidades e relações de causa e efeito se encontrariam difusas ou excessivamente simplificadas, como efeito de um noticiário no qual elas não foram objeto de atenção apropriada, e no qual a ideia de política se reduziria a um jogo escuso motivado por intenções não assumidas de obtenção de vantagens pessoais pelos políticos. 
ROTHBERG, D. Enquadramentos midiáticos e sua influência sobre a consolidação de...

Nesse sentido, os enquadramentos, ao conter algumas informações e não outras, seriam capazes de induzir a uma compreensão específica da atuação do poder público como agente improvável, se não impossível, de formulação democrática de linhas de ação para a busca pelo bem-estar coletivo.

Embora autores como Cappella e Jamieson (1997) sustentem em bases empíricas as razões para considerar o enquadramento como teoria dos efeitos de mídia, a pesquisa de framing na atualidade assume que os efeitos não podem ser dados como certos e, assim, ainda persegue o refinamento de teorias e métodos (MATTHES, 2012; D’ANGELO, 2012). Por isso, torna-se adequada, sempre que possível em função dos recursos humanos, materiais e financeiros disponíveis, a realização de pesquisas empíricas voltadas a conhecer como diferentes públicos lidaram com os frames aos quais foram expostos. Não obstante, permanece a relevância das pesquisas circunscritas à identificação e à compreensão dos enquadramentos presentes em dadas coberturas jornalísticas. Essas investigações, embora não possam dar indicações mais precisas sobre o comportamento do público diante das notícias, são extremamente necessárias, porque contribuem para indicar a potencial contribuição do jornalismo para o aprofundamento da cidadania em sua dimensão do direito à informação sobre temáticas de grande relevância nas democracias contemporâneas.

Os enquadramentos jornalísticos devem ser pensados como contribuição à formação da cultura política do país, que pode assumir papel tão relevante na manutenção da vida social quanto as próprias instituições políticas formais. Afinal, as instituições políticas podem não ser, isoladamente, capazes de promover as transformações por elas pretendidas. As características da cultura política de um país podem facilitar ou trazer resistência à efetivação das mudanças (ABU-EL-HAJ, 1999; HALL; TAYLOR, 2003).

Por isso, torna-se necessário rastrear indícios de uma cultura política que possa influenciar o desempenho das instituições políticas, como legislações e estruturas criadas por força de lei, como é o caso do Estatuto da Criança e do Adolescente e o correspondente sistema nacional de atendimento socioeducativo. Ou seja, se uma nova legislação, por si só, pode não ser capaz de promover as modificações desejadas na realidade social, torna-se relevante apurar os traços de cultura política potencialmente capazes de trazer obstáculos à implementação da lei.

Dada a centralidade da mídia como potencial formadora de uma cultura política que contém juízos morais e apreciações genéricas sobre regras sociais amparadas nas instituições políticas, a pesquisa de enquadramentos se revela necessária para sinalizar a disposição de uma sociedade nacional em aceitar as implicações sociais de uma legislação específica como o Estatuto da Criança e do Adolescente.

\section{Metodologia}

O arquivo dos textos de $O$ Estado de $S$. Paulo é de acesso gratuito e está disponível em $<$ www.estadao.com.br>. Também foi utilizado o acervo digital da versão impressa, disponível somente a assinantes em <servicos.estadao.com.br/login>.

Os arquivos de textos e a versão impressa da Folha de $S$. Paulo utilizados estão disponíveis somente a assinantes em <www.folha.uol.com.br/fsp >.

A análise de enquadramento exigiu a identificação de três componentes essenciais dos textos estudados: i) seleção, ii) ênfase e iii) exclusão de informações relativas a questões, fatos e 


\section{OPINIÃO PÚBLICA, Campinas, vol. 20, no 3, dezembro, 2014, p. 407-424}

acontecimentos enfocados. Esse procedimento foi realizado com o auxílio de planilhas eletrônicas, considerando os seguintes aspectos:

i) A seleção de informações operada por um texto pode ser apreendida através das tarefas de identificação e descrição das principais temáticas ali relacionadas, considerando-se que as escolhas efetivas ocorreram dentro de uma gama possível de opções. A presença de certas temáticas em um dado texto é um indicador da valorização de tendências políticas, econômicas e sociais.

ii) A ênfase de informações em um texto pode ser apurada pela identificação e descrição dos significados presentes nos elementos de maior destaque, como título, lide (introdução) e pontos estratégicos salientados por elementos de progressão textual.

iii) A identificação das informações excluídas em um texto exige relacionar, em primeiro lugar, aspectos que, em função do foco, das temáticas selecionadas e da ênfase ali detectada, seriam necessários para permitir uma compreensão abrangente do fato ou acontecimento em questão, com seus aspectos intrínsecos nas dimensões política, social e econômica. Em seguida, em contraste entre tal relação e o conjunto de informações efetivamente apresentado pelo texto, podem ser identificados os conteúdos que permaneceram ausentes.

A análise classificou os textos por sua característica principal em enquadramentos episódicos e temáticos, que, conforme a literatura revisada, são verificáveis empiricamente como formatos específicos de cobertura jornalística que se colocam em polos opostos. Fatos relevantes do percurso de definição e execução de políticas públicas sofrem a tendência de ser representados pelo jornalismo comercial sob a forma de enquadramentos episódicos, que mal tocam nas questões propriamente políticas do fato, ligadas à complexidade das escolhas envolvidas em determinada opção a ser adotada ou rejeitada pela gestão pública, e apenas acentuam aspectos circunstanciais dos fatos enfocados. Já os enquadramentos temáticos abrangem aspectos concretos das políticas públicas envolvidas nas escolhas eleitorais, ações e decisões de mandatários, conferências nacionais e internacionais, votações parlamentares, arranjos partidários, implementação de novas medidas legais etc. Uma cobertura centrada em temas exige que os jornalistas saibam situar os diversos aspectos das políticas públicas em seu devido contexto. Eles devem explorar as relações entre antecedentes e consequências segundo diferentes perspectivas, considerando as expectativas das pessoas afetadas e os resultados previstos de acordo com visões diversas, além de examinar influências macroestruturais, tendências históricas, alternativas, possibilidades, exemplos de outras regiões ou países, possíveis obstáculos etc.

O pluralismo, característica central dos enquadramentos temáticos, corresponde a um tratamento compreensivo de causas, consequências e da diversidade de fatores que concretamente influenciam a definição e a implementação de políticas públicas.

Em análise inicial exploratória da amostra selecionada, verificou-se que a adoção de uma categorização dual de enquadramentos episódicos versus enquadramentos temáticos se mostraria adequada para a análise proposta. A razão de tal categorização se assenta sobre a percepção de que a temática da preservação dos direitos de crianças e adolescentes esteve sujeita, no período analisado, a uma cobertura em que se verificou uma discreta maioria de enquadramentos episódicos, com presença relativamente menor na forma de enquadramentos temáticos, permanecendo ausentes da amostra os demais formatos de enquadramento. 
ROTHBERG, D. Enquadramentos midiáticos e sua influência sobre a consolidação de...

Empiricamente, as informações dos enquadramentos temáticos foram agrupadas em duas direções, bastando a presença de uma delas para justificar a classificação temática, a saber:

a) Causas, soluções e políticas públicas. Verificou-se a maneira pela qual a matéria analisada traçou conexões entre as causas da violação dos direitos da infância e da adolescência e as soluções cabíveis e apresentou propostas para resolver o problema, seja de forma pontual ou com referência às políticas públicas sociais do sistema de preservação dos direitos da criança e do adolescente.

b) Dados e discussões específicas. Verificou-se a presença de estatísticas, citações complementares à legislação atual, possíveis menções a temas correspondentes à área e informações que ampliaram o contexto de compreensão do fato imediato.

\section{Resultados e discussão}

A amostra de matérias jornalísticas publicadas pelos jornais Folha de S. Paulo e O Estado de $S$. Paulo no período de julho de 2008 a dezembro de 2009 que se referiram nominalmente ao Estatuto da Criança e do Adolescente se caracterizou pela presença de 120 textos, dos quais 78 são de O Estado de S. Paulo e 42 da Folha de S. Paulo.

Os resultados da análise de enquadramento da amostra assim compreendida sugerem a confirmação parcial das hipóteses iniciais da pesquisa. Foi detectada uma discreta maioria de textos informativos publicados na forma de enquadramentos episódicos. São, no total dos dois jornais, 64 textos informativos com enquadramentos episódicos, ou 54,24\% da amostra, diante de 54 textos informativos com enquadramentos temáticos (45,76\%).

Há diferenças importantes entre os jornais. O Estado de $S$. Paulo é o jornal em que o enquadramento episódico ao tema estudado foi maior, com 45 matérias (57,69\% do total), diante de 33 matérias com enquadramento temático (42,31\%).

No Estadão, os enquadramentos episódicos foram verificados em matérias curtas, com 1,5 a 2,5 mil caracteres, aproximadamente (com espaços), em geral circunscritos a notícias de acontecimentos imediatos como abuso sexual e agressões contra crianças e adolescentes, maus-tratos em unidades de atendimento socioeducativo a esse público e alegadas infrações cometidas por adolescentes, como participação em roubos, assaltos e tráfico de drogas. A maioria (82,22\%) das 45 matérias com enquadramento episódico apenas citou o Estatuto da Criança e do Adolescente como legislação responsável pelo encaminhamento de crianças e adolescentes às instâncias de atendimento desse público, sem aprofundar as suas funções ou apresentar informações que situem causas e soluções no contexto das políticas públicas do sistema de preservação dos direitos.

Já os enquadramentos temáticos estiveram presentes em O Estado de $S$. Paulo em matérias de 3 a 6,5 mil caracteres, aproximadamente (com espaços), com enfoque em ações abrangentes do poder público para conter a exploração sexual de crianças e adolescentes e preservar direitos desse público em unidades de atendimento socioeducativo e em contextos familiares e sociais diversos.

No Estadão, o tratamento temático esteve ancorado na apresentação de informações que situaram causas e soluções no contexto das políticas públicas do sistema de preservação dos direitos da criança e do adolescente. Com frequência, o ponto de partida das matérias envolveu aspectos relacionados às políticas públicas de preservação de direitos, como a perspectiva de uma mudança na legislação que afeta crianças e adolescentes trazida pelo projeto de lei 3.773, então aprovado pela 


\section{OPINIÃO PÚBLICA, Campinas, vol. 20, no 3, dezembro, 2014, p. 407-424}

Câmara dos Deputados, que aumenta o rigor das penas para pornografia infantil e crimes de abuso sexual; a implantação do chamado toque de recolher em cidades do interior de São Paulo, proibindo a circulação de adolescentes após determinados horários; e mudanças no cumprimento de medidas socioeducativas, como a perspectiva da municipalização da liberdade assistida anunciada pelo governo do estado de São Paulo.

Em sua maioria (três em cada quatro), as matérias com enquadramento temático apresentaram dados e discussões específicas que aprofundam o contexto para o leitor, como comparações, análises adicionais, fontes complementares etc.

A amostra da Folha de S. Paulo apresentou, em comparação com a amostra de $O$ Estado de $S$. Paulo, um tratamento de qualidade discretamente superior: foram 21 matérias com enquadramento temático (52,50\% do total) e 19 matérias com enquadramento episódico (47,50\%).

Das 19 matérias da Folha de $S$. Paulo com enquadramento episódico, que possuem entre 1 e 2,7 mil caracteres, aproximadamente (com espaços), 16 (84,21\%) apenas citaram o Estatuto da Criança e do Adolescente como legislação de referência para o fato enfocado, sem outras informações sobre as funções das medidas socioeducativas ali previstas e os critérios de sua aplicação, o contexto social de eventuais infrações noticiadas etc., e não possuem dados ou discussões adicionais. São enfoques noticiosos sobre acontecimentos como furtos e agressões alegadamente cometidos por adolescentes, denúncias de exploração sexual e má gestão de entidades de execução de medidas socioeducativas.

A totalidade das 21 matérias da Folha com enquadramento temático, que contêm entre 1,7 e 5,5 mil caracteres (com espaços), possui informações que situaram causas e soluções no contexto das políticas públicas do sistema de preservação dos direitos da criança e do adolescente, e 19 (90,47\%) delas apresentaram dados e discussões adicionais. São matérias sobre assuntos como saúde e comportamento de jovens; gestão de conselhos tutelares; atualização da legislação pertinente diante de fatores como o anonimato na internet; denúncias de agressão em unidades da Fundação Casa (Centro de Atendimento Socioeducativo ao Adolescente); e estudos e eventos que trazem novos dados sobre o sistema de preservação de direitos de crianças e adolescentes.

De maneira geral, verifica-se que enquadramentos temáticos estiveram sustentados pela apresentação de informações abrangentes que relacionam causas e soluções de violações de direitos de crianças e adolescentes no contexto das políticas públicas pertinentes. Nesse sentido, a qualidade da contextualização que subjaz aos enquadramentos temáticos tendeu a se mostrar decisiva para que o potencial informativo de uma abordagem jornalística fizesse jus ao quadro atual das políticas envolvidas no sistema nacional de atendimento àquele público, que conferem direitos de cidadania alinhados à consolidação da democracia brasileira.

Em sentido oposto, os enquadramentos episódicos figuraram desprovidos de informações adequadas e, em geral, apenas citaram a existência do Estatuto da Criança e do Adolescente como legislação que regula o setor, sem mais esclarecimentos sobre as políticas públicas da área, o que pode dificultar a percepção de um contexto de reconhecimento de direitos considerado um dos avanços para o aprofundamento da cidadania no país.

No jornal O Estado de S. Paulo, os enquadramentos episódicos são mais frequentes nas matérias jornalísticas, correspondendo a $57,69 \%$ do total. Já na Folha de S. Paulo, foi detectado um quadro discretamente diferenciado, com $47,50 \%$ das matérias com enquadramento episódico. 
ROTHBERG, D. Enquadramentos midiáticos e sua influência sobre a consolidação de...

A persistência de enquadramentos episódicos em toda a amostra analisada sugere a confirmação parcial das hipóteses da pesquisa, segundo as quais o Estatuto da Criança e do Adolescente, mesmo após 18 anos de sua promulgação, enfrenta resistências à sua consolidação, provenientes em parte dos enquadramentos simbólicos perpetrados pelo jornalismo sujeito à exploração comercial.

Em síntese, os resultados sugerem que o jornalismo comercial no estado de São Paulo pode ter dificultado o aprofundamento da cultura política de reconhecimento de direitos sociais, através da veiculação de matérias jornalísticas nas quais se revelou insuficiente a qualidade da contextualização de informações em relação ao sistema nacional de preservação dos direitos de crianças e adolescentes, aos atores sociais envolvidos e a dados e discussões específicas relacionadas, como esclarecimentos sobre a gestão das instituições de execução de medidas socioeducativas.

Essa interpretação dos resultados é sustentada pelo conceito de enquadramento, que envolve os aspectos de representação, narrativa mitológica e efeitos de mídia. Os enquadramentos episódicos detectados carregam representações inscritas em narrativas mitológicas de uma sociedade atomizada, na qual os adolescentes alegadamente infratores são os únicos responsáveis por sua marginalização, e o que resta ao poder público é puni-los com o banimento e a reclusão. A cultura política construída nesse sentido é de ausência de responsabilidade do Estado pela preservação de direitos sociais, embora estes estejam assegurados pelo Estatuto da Criança e do Adolescente. Já os enquadramentos temáticos, ao estarem associados a narrativas de uma sociedade caracterizada pela presença de estruturas específicas de preservação de direitos garantidos por lei, favoreceriam a construção de uma cultura política de responsabilização do poder público pela ineficácia de suas ações destinadas a atender a leis democraticamente formuladas pela sociedade.

Ou seja, os jornais analisados podem ser responsabilizados por oferecer uma contribuição relativa à afirmação da cidadania no Brasil, ao empregar, com frequência, determinados conceitos de notícia como vetores de coberturas superficiais e fragmentadas de fatos e acontecimentos que, à luz do ECA, deveriam ser contextualizados em relação às políticas públicas da área e seus nexos estabelecidos entre causas possíveis e soluções cabíveis.

Mas é forçoso reconhecer que, nos jornais estudados, as resistências à consolidação de uma cultura política favorável à afirmação de direitos sociais não parecem ser absolutas, dada a proporção significativa de enquadramentos temáticos na amostra analisada. Os números da pesquisa sugerem que houve um esforço importante dos veículos na qualidade de seu jornalismo, através da construção de enquadramentos temáticos.

\section{Considerações Finais}

Os enquadramentos identificados e descritos por levantamentos sistemáticos em um período abrangente compõem um indicador da cultura política de reconhecimento de direitos daquele público. Nesse contexto, se uma legislação como o Estatuto da Criança e do Adolescente (ECA) deve conduzir à criação de estruturas aperfeiçoadas de preservação de direitos, mas as ações do poder público não são suficientes para gerar os efeitos sociais esperados, a resistência à efetivação da lei pode vir em parte de certas concepções sociais que permaneceriam infensas à lei, das quais os enquadramentos midiáticos podem ser um indicador. 
Crianças e adolescentes em situação de vulnerabilidade, que dependem diretamente da legislação específica que protege seus direitos, formam um público especialmente sujeito a representações inscritas em narrativas mitológicas específicas. Isso porque a perspectiva de ressocialização presente no ECA exige que medidas punitivas sejam substituídas por medidas socioeducativas, que, por sua vez, implicam a mudança do paradigma cultural, consolidado em um contexto histórico-social passado, que associava o suposto desvio da conduta do adolescente à exigência de enfrentamento correcional e punitivo.

Pode-se dizer que a notícia que tem seu foco central sobre um suposto desvio de conduta de um adolescente, desprovido de informações sobre o contexto legal de preservação de seus direitos sociais, evoca o contexto das medidas punitivas vigentes no quadro anterior à promulgação do ECA, segundo as quais o adolescente marginalizado incorria em crime e merecia, enquanto sujeito irrecuperável, punição na forma de banimento e reclusão. O enquadramento episódico em torno de um acontecimento como um alegado roubo cometido por adolescentes instaura um quadro de compreensão específico, no qual são relegadas as condições de exclusão social e permanecem invisíveis os direitos assegurados pela legislação.

As representações contidas no enquadramento episódico podem acentuar a responsabilidade do próprio adolescente sobre a suposta infração cometida, além de construir um cenário de ausência de responsabilidade do poder público sobre o contexto social mais amplo de exclusão de oportunidades de inserção adequada dos jovens nas esferas da educação e do trabalho. Tal frame se associa a uma representação de sociedade atomizada, com diluída consciência histórica e frágil percepção da conquista representada pelos direitos de cidadania inscritos em suas próprias leis, na qual prospera a narrativa mitológica da responsabilização individual diante da aparente ausência de direitos sociais.

Já o enquadramento temático, ao situar o adolescente no contexto de seus direitos assegurados pelo ECA, tende a promover a responsabilização do poder público pela ineficácia de suas ações que deveriam atender ao disposto na lei. O enquadramento temático, ao apresentar informações que situam causas e soluções no contexto das políticas públicas do sistema de preservação dos direitos da criança e do adolescente, além de dados e discussões específicas que ampliam a contextualização do fato, pode gerar efeitos diferenciados.

Ou seja, o enquadramento temático pode conduzir à construção de uma visão sobre os problemas sociais na qual a responsabilidade por alegadas infrações cometidas por adolescentes não está centrada no próprio infrator, mas sim envolve uma sociedade nacional que assentiu democraticamente em torno da promulgação de uma lei destinada a reverter as consequências históricas de níveis excepcionais de iniquidade social. A narrativa contida nas representações do enquadramento temático dá conta de uma sociedade dotada de estruturas dirigidas a zelar pelo atendimento dos direitos de cidadania, na qual o bem. estar coletivo depende de sujeitos em formação terem essa condição respeitada pelas instituições sociais.

Embora seja recomendável, no contexto teórico do conceito de framing, que a ocorrência dos efeitos de enquadramentos episódico e temático seja verificada através de pesquisas qualitativas de recepção, é igualmente autorizada pela teoria a premissa de que efeitos assim esperados são coerentes com resultados obtidos anteriormente de maneira empírica e com as proposições teóricas da psicologia cognitiva que fundamentam o conceito. Ou seja, se não há prova cabal de que determinados enquadramentos gerem efeitos líquidos e certos, há lastro teórico e empírico para indicar que é 
ROTHBERG, D. Enquadramentos midiáticos e sua influência sobre a consolidação de...

coerente, com o estado atual do conhecimento na área, a expectativa de determinados efeitos. Daí a multiplicação de estudos circunscritos à pesquisa de enquadramentos, sem desdobramentos qualitativos.

Os resultados da pesquisa aqui descrita sugeriram a confirmação parcial de suas hipóteses iniciais, segundo as quais o Estatuto da Criança e do Adolescente, apesar de ter completado, em julho de 2008, 18 anos de sua promulgação, enfrenta resistências à sua consolidação, possivelmente acentuadas por coberturas jornalísticas superficiais e fragmentadas de fatos e acontecimentos que, à luz da legislação, deveriam ser contextualizados em relação às políticas públicas da área e seu específico entendimento de causas possíveis e soluções cabíveis.

As análises realizadas pela pesquisa indicam a persistência de enquadramentos desfavoráveis ao fortalecimento de uma cultura política de reconhecimento de direitos de crianças e adolescentes. Mas foi detectado um número significativo de matérias jornalísticas com contextualização adequada, o que sugere a existência de oportunidades de aperfeiçoamento da qualidade jornalística.

O amadurecimento do jornalismo, pensado como instituição, torna-se uma possibilidade se o tema da qualidade vier à tona no dia a dia das decisões rápidas tomadas em uma redação. Pluralidade e contextualização na forma de enquadramentos temáticos, embora possam ser eventualmente reconhecidos como necessários pelos profissionais da área, com frequência se tornam ideais inatingíveis. Mas uma das saídas para o fortalecimento do papel do jornalismo em direção ao atendimento do direito à informação nas democracias contemporâneas pode estar, justamente, no fortalecimento de uma cultura política de reconhecimento de direitos sociais, que exija nada menos que profundidade e contexto adequados nas matérias sobre fatos e acontecimentos relacionados à preservação de direitos de crianças e adolescentes.

Novas pesquisas são necessárias para verificar se esse esperado percurso de aperfeiçoamento se tornará progressivamente realidade. Investigações no nível da recepção de notícias, com métodos qualitativos como entrevistas e grupos focais, também serão úteis para auxiliar a compreensão dos efeitos de mídia no caso particular da cobertura jornalística sobre a temática em questão.

\section{Referências Bibliográficas}

ABU-EL-HAJ, J. "O debate em torno do capital social: uma revisão crítica". B/B - Revista Brasileira de Informação Bibliográfica em Ciências Sociais, Rio de Janeiro, vol. 47, p. 65.79, 1º semestre de 1999.

ALDÉ, A. "A construção da política: cidadão comum, mídia e atitude política". Rio de Janeiro. Tese de Doutorado em Ciência Política. Instituto Universitário de Pesquisas do Rio de Janeiro, 2001.

Azevedo, F. A. Agendamento da política. In: Rubim, A. A. C. (org.). Comunicação e política: conceitos e abordagens. São Paulo: Unesp; Salvador: Edufba, 2004

BARTHES, R. Mitologias. Rio de Janeiro: Bertrand do Brasil, 1993.

BIRD, S. E.; DARDENNE, R. W. Mito, registro e "estórias": explorando as qualidades narrativas das notícias. In: TRAQUINA, N. (org.). Jornalismo: questões, teorias e "estórias". Lisboa: Veja, 1999.

Bobbio, N.; Matteuci, N.; PAsquino, G. Dicionário de política. Brasília: Editora UnB, 1997.

BouRdieu, P. O poder simbólico. Rio de Janeiro: Bertrand Brasil, 1998. 


\section{OPINIÃO PÚBLICA, Campinas, vol. 20, no 3, dezembro, 2014, p. 407-424}

BouRdieu, P.; PASSERON, J. A reprodução: elementos para uma teoria do sistema de ensino. Rio de Janeiro: Francisco Alves, 1982.

CApPella, J. N.; Jamieson, K. H. Spiral of cynicism: the press and the public good. Oxford, UK: Oxford University Press, 1997.

D'ANGELO, P. "Studying framing in political communication with an integrative approach". American Behavioral Scientist, Thousand Oaks, CA, vol. 56, n 3, p. 353-364, March, 2012.

FrançA, V. Representações, mediações e práticas comunicativas. In: PereIRA, M.; Gomes, R. C.; FigueIRedo, V. L. F. (orgs.). Comunicação, representação e práticas sociais. Rio de Janeiro: PUC-Rio; Aparecida, SP: Ideias e Letras, 2004.

Gamson, W. A.; ModiglianI, A. "Media discourse and public opinion on nuclear power: a constructionist approach". The American Journal of Sociology, Chicago, vol. 95, n 1, p. 1.37, July, 1989.

HALL, S. The work of representation. In: London: Sage; Milton Keynes: Open University, 2002.

(ed.). Representation: cultural representations and signifying practices.

Hall, P. A.; TAyloR, R. C. R. "As três versões do neo-institucionalismo". Lua Nova, São Paulo, n 58, p. 193.223, 2003.

IYENGAR, S. "The accessibility bias in politics: television news and public opinion". International Journal of Public Opinion Research. Oxford, UK, vol. 2, n 1, p. 1-15, Spring, 1990.

Is anyone responsible? How television frames political issues. Chicago: The University of Chicago Press, 1991.

LıMA, V. A. Mídia: teoria e política. São Paulo: Fundação Perseu Abramo, 2001.

MATTHES, J. "Framing politics: an integrative approach". American Behavioral Scientist, Thousand Oaks, CA, vol. 56, n³, p. 247.259, March, 2012.

MotTA, L. G. Enquadramentos lúdico-dramáticos no jornalismo: mapas culturais para organizar narrativamente os conflitos políticos. In: MIguel, L. F.; BIRoLI, F. (orgs.). Mídia, representação e democracia. São Paulo: Hucitec, p.137. 151,2010

NECO, E. "ANJ divulga ranking dos jornais com maior circulação diária em 2008". Disponível em: <http://portalimprensa.uol.com.br/portal/ultimas_noticias/2009/04/14/imprensa27429.shtml>. Acesso em: 3 ago. 2009 .

Porto, M. Enquadramentos da mídia e política. In: RubIM, A. A. C. (org.). Comunicação e política: conceitos e abordagens. São Paulo: Unesp; Salvador: Edufba, 2004.

"Framing controversies: television and the 2002 presidential election in Brazil". Political Communication, New York, vol. 24, $n^{\circ} 1$, p. 1.38, February, 2007a.

"Frame diversity and citizen competence towards a critical approach to news quality". Critical Studies in Media Communication, New York, vol. 24, nº 4, p. 303.321, December, 2007b.

SCHEUfele, D. "Framing as a theory of media effects". Journal of Communication, Hoboken, NJ, vol. 49, n 1, p. 103.122, February, 1999.

SOARES, M. C. Representações, jornalismo e a esfera pública democrática. São Paulo: Cultura Acadêmica, 2009.

SodRÉ, M. A narração do fato: notas para uma teoria do acontecimento. Petrópolis, RJ: Vozes, 2009.

Tuchman, G. Contando "estórias". In: TRaQuINA, N. (org.). Jornalismo: questões, teorias e "estórias". Lisboa: Vega, 1999.

Danilo Rothberg·danroth@uol.com.br

Submetido à publicação em outubro de 2013. Aprovado para publicação em julho de 2014. 